\title{
Income's Association with Judgments of Life Versus Feelings
}

\author{
Ed Diener \\ University of Illinois \\ Daniel Kahneman \\ Princeton University \\ William Tov \\ Singapore Management University \\ Raksha Arora \\ The Gallup Organization
}

Draft Date: February 23 ${ }^{\text {rd }}, 2009$

\section{Citation:}

Diener, E., Kahneman, D., Tov, W., \& Arora, R. (2010). Income's association with judgments of life versus feelings. In E. Diener, D. Kahneman, \& J. F., Helliwell (Eds.), International differences in well-being (pp. 3-15). Oxford, UK: Oxford University Press.

Send reprint requests to: Ed Diener

Department of Psychology

University of Illinois

603 E. Daniel Street

Champaign, IL 61820

U.S.A. 


\begin{abstract}
$\underline{\text { Abstract }}$
Evidence is presented that measures of subjective well-being vary along a dimension anchored at the two ends by evaluative judgments of life and experienced affect. A debate in recent decades has been focused on whether rising income increases the experience of well-being. We found that Judgment is more strongly associated with income, and with long-term changes of national income. Measures of feelings showed lower correlations with income in cross-sectional analyses, and lower associations with long-term rising income. Furthermore, income showed very similar regression lines with the judgment of life at the two times of the surveys, suggesting that a common standard was used. Measures of concepts such as "Happiness" and "Life Satisfaction" appear to be saturated with varying mixtures of judgment and affect, and this is reflected in the degree to which they correlate with income. Our findings are relevant to Easterlin's hypotheses about income and well-being. Income and income change were associated with judgments of life and national increases in them, whereas the associations of income and feelings were less robust.
\end{abstract}


Income's Association with Judgments of Life Versus Affect

Attention has recently been drawn to the fact that "happiness" is actually not a single entity, and can be divided into distinct elements. Kahneman (1999) suggested that global judgments such as an evaluation of "life satisfaction" computed and reported at a single moment in time are fundamentally different than the pleasantness of people's emotional lives. In support of this distinction, Lucas, Diener, and Suh (1996) found that various forms of subjective well-being are empirically separate. Thus, it is no longer sufficient to simply discuss and study well-being; the various forms of well-being must be assessed and analyzed.

The major distinction that Kahneman described was between global evaluative judgments and people's feelings of pleasure and displeasure summated over time. We suggest that the various self-report measures of subjective well-being are saturated to varying degrees with judgment and affect. Although perhaps no well-being measure is totally free of either of these components, it is plausible that a global measure of "life satisfaction" taken at one point in time might be more heavily weighted with judgment, whereas reports of "happiness" might be more saturated with affect. In the present study we were fortunate to have two measures that appeared a priori to be toward the two ends of the judgment-affect dimension, Cantril's Ladder (1965) and a report of yesterday's affect. We analyzed two additional measures, life satisfaction and happiness, that we predicted would fall between the Ladder and affect scales on the judgment-affect dimension, but each closer to the opposite poles.

One goal of our study was to determine whether judgment and affect measures perform differently and to identify the mix of the two processes reflected in certain 
scales. We examined the intercorrelations among the measures at both the individual and national levels, as well as their correlations with external variables such as income. We also examined how the measures changed over time in response to movements in income. In this way we aimed to explore the correlates of affect versus judgment measures of well-being.

In a classic 1974 article Richard Easterlin asked whether economic growth improves "the human lot," and he focused on "happiness" to answer the question. The "Easterlin Paradox" is the paradoxical fact that differences between people in income are usually correlated with reports of well-being, but as national incomes grew there often was not substantial growth in well-being. Much debate has ensued about whether nations have in fact risen in average well-being over time in response to increasing income.

Hagerty and Veenhoven (2003), Stevenson and Wolfers (2008), and Inglehart, Foa, Peterson, and Welzel (2008) all claimed that on the whole the evidence suggests that there was increasing subjective well-being in many nations, and that this was associated with rising incomes. An examination of the data reported in these articles, however, indicates variability in the findings. For example, in a response to Hagerty and Veenhoven, Easterlin (2005) pointed out that many nations in fact grew in income over time and did not increase in well-being. Easterlin presented reports of happiness over the decades in the United States, which were essentially flat, and contrasted that pattern with the substantial economic growth the country experienced during the same period of time. He concluded that across nations there are "disparate trends in happiness, suggesting that factors other than growth in income are responsible for the differential trends in happiness" (p. 429). In response, Veenhoven and Hagerty (2006) suggest that on average 
happiness increases occurred in nations where income rose the most. Stevenson and Wolfers argue that increasing income has led to increases in happiness, but they also point to the substantial statistical uncertainty in a few of their conclusions.

Inglehart (2008) suggested that life satisfaction might be more influenced by economic conditions than is happiness, and this suggestion forms the starting point for our income analyses. We examine the possibility that various forms of well-being vary in their responsiveness to income change. Specifically, it could be that judgments and affective well-being vary in how much they are associated with economic growth. We analyze the correlation of four well-being variables that we hypothesize lie along the judgment versus affect dimension, with several economic variables - income, income change, and the ownership of modern conveniences such as television. Thus, we explore whether some of the past differences in conclusions about the money-happiness relation are due to the differential association of various types of well-being with income.

To examine income change and well-being change, we examined income changes over the interval from an early survey to a later survey for each type of well-being. The minimum for inclusion in our analysis was a period greater than five years, and the average for each of the measures was an interval of several decades. We selected the surveys for each type of well-being measure that were the most distant from each other in time, and used the incomes for the corresponding years for each nation.

We were fortunate in this study to have a representative sample of virtually the entire adult population of the world. Unlike many previous studies, the Gallup World Poll (GWP) includes many less economically developed nations, and a representative sample of rural residents outside the major metropolitan areas of these nations. We were also 
fortunate that the survey included both a global judgment of life measure and an assessment of emotions experienced "yesterday." One issue with past research is that the wording of questions is different in various surveys conducted over the decades. Thus, we focused on surveys that used very similar or identical wording and the same response formats.

In our analyses we relied most heavily on the analyses of national data, not individual data, for several reasons. First, we have longitudinal data over time only for nations and this is a keystone of our analyses. Second, the Easterlin claim about income change is that in the aggregate at the societal level income increases do not raise wellbeing, because as the income of everyone rises the standard for adequate income also rises. Thus, our analyses focus on the nation level, but we also examined individual data in the Gallup World Poll to determine whether the same dimensionality can be found in the well-being measures, and whether the predictors are the same as at the nation-level.

In sum, there were two goals in the current study. First, we analyzed measures of well-being to determine whether they are separable, but associated in a way reflecting an underlying dimension related to global evaluative judgments versus the ongoing experience of affect. Second, we examined income and other predictors to determine whether they are most related cross-sectionally to the judgment versus affective ends of the well-being dimension, and whether income changes relate more to judgment or to affect.

\section{Methods}

The Gallup Organization initiated its World Poll in 2005 and the first wave conducted from late 2005 to 2006 includes representative surveys of 132 societies 
accounting for about $96 \%$ of the world's population. The poll features a consistent set of standard questions in all surveys and uses nationwide samples (with the exception of Angola, Myanmar and Cuba where only urban populations were surveyed; and Afghanistan where there were representative provinces). Two sampling procedures were used in the World Poll: random-digit-dial (RDD) telephone surveys and face-to-face interviews. The RDD design was used in countries where the vast majority of the population has access to land line telephones. In all other countries, face-to-face surveys were conducted with clusters of households (obtained from census tract listings) serving as the basis for random sampling. The typical World Poll survey in a country consisted of approximately 1,000 respondents. The total sample size for the Wave 1 World Poll was 140,658 .

Wave 2 of the survey (2007) presented an additional well-being question on life satisfaction that was not included in the first wave. Thus, we analyzed the association of the well-being measures at the individual level using Wave 2, which included 113,872 respondents from 105 nations. Approximately 55,497 respondents were presented with the life satisfaction question.

We used two measures of well-being from Wave 1 of the Gallup World Poll. Cantril's Ladder (1965) asks respondents to evaluate their life on a scale from 0 (worst possible) to 10 (best possible). The item queries respondents as to which step on the ladder they feel that they personally stand at the present time. Another measure assesses the recent experience of emotions, namely, positive feelings (enjoyment and smiling/laughter) and negative feelings (sadness, anger, worry, and depression). To reduce the extent of bias in recalling past experiences, respondents reported (yes or no) 
whether they experienced lots of these feelings during the previous day. We averaged Enjoyment and Smiling and subtracted the average of the four negative emotions to create an Affect Balance score. We averaged the individual scores to create nation-level scores after weighting the individual scores by sample demographic weights to bring the nation scores as close as possible to representativeness. The additional measure of wellbeing in Wave 2 on Life Satisfaction asked respondents how satisfied they were with their lives on a scale ranging from 0 (Dissatisfied) to 10 (Satisfied).

The Gallup World Poll also queried respondents about their ownership of modern household conveniences, and we averaged four of these to create a composite Conveniences score -electricity, telephone, television, and computer. In addition, we analyzed a question that asked how free subjects were in deciding how to spend their time. The question was answered on a binary Yes-No response scale and asked: "Were you able to choose how you spent your time all day yesterday?"

In addition to the Gallup World Poll, we also obtained well-being measures for nations from Veenhoven's (2008) World Database on Happiness. We searched for those nations where the same 4-point happiness question was asked at two points in time separated by more than five years. When the scale had been administered more than two times, we used the first and last administrations. The question asked: Taking all things together, would you say you are: 4 - Very happy, 3 - Quite happy, 2 - Not very happy, or 1 - Not at all happy. We used variants of this scale where the identical scale and responses had been used at both points in time. For example, in some administrations of the scale the 3 response is labeled "pretty happy." We used scores from these variations if the identical scale was used in that nation at two points in time more than five years apart. 
We also obtained Time 1 scores for nations where Cantril's Ladder had been administered previously, and used the oldest date where the 0 to 10 response format was employed. There were often small changes in the Cantril scale from the earlier to later administration. For instance, the early administration often showed steps ascending a mountain whereas the later administration simply showed a ladder with steps. For life satisfaction Time 1 we used the oldest administration in each nation where the same 0 to 10 format was used as in the Gallup World Poll. However, in order to increase our number of nations for life satisfaction we also used instances where the response format was 1 to 10, as long as earlier and later dates were available using the same response scale, which were separated by more than five years. One nation, the Dominican Republic, was dropped from the analyses of the Ladder scale because its score was an extreme outlier, far lower than any score ever reported. The score was so low that we suspect that it is an error, or a temporary response to some acute disaster.

Although there are several sources that provide GDP per capita data, they differ in the years for which data are available. Given that our dataset spanned a over three decades, we sought a single source of GDP per capita estimates rather than drawing from different sources that may differ in terms of their estimation methods. Therefore, we used income data from Maddison (2007), who provided a broad coverage of estimates for GDP per capita adjusted for purchasing power parity in 1990 international dollars.

\section{Results}

Our general plan was to first use the large GWP to examine how well-being measures are related to one another cross-sectionally at a point in time. We next analyzed how they relate to predictors such as income. These analyses were computed at both the 
national and individual levels. In the second set of analyses we examined how national changes in income over time are associated with country-level changes in the well-being measures. We also analyzed the magnitude of the changes in well-being.

\section{$\underline{\text { Cross-Sectional Analyses }}$}

Our analyses begin with cross-sectional correlations among the well-being measures themselves, to explore their relations to each other. We correlated the nationlevel well-being averages for four measures of well-being at the most recent time of the surveys.

We further explored at the nation-level the composition of Life Satisfaction and Happiness by predicting them simultaneously with both the Ladder and Affect Balance scores of nations. Life Satisfaction was predicted most strongly by the Ladder Score $($ Beta $=.67, \underline{p}<.01)$, although Affect Balance also significantly added to the prediction $($ Beta $=.27, \mathrm{p}<.01)$. When the predictors are entered in a sequential manner, the Ladder accounted for 33\% of the variance in Life Satisfaction beyond Affect Balance, whereas Affect Balance accounts for only 5\% when the Ladder is entered first. Together these two measures account for $71 \%$ of the variance in the Life Satisfaction of nations. Happiness was also predicted by the Ladder (Beta .36, $\mathrm{p}<.01$ ), with the Affect Balance also predicting positively $($ Beta $=.48, \underline{p}<.01)$. When entered sequentially, the Ladder accounted for $8 \%$ of the variance in Happiness beyond Affect Balance, whereas Affect Balance accounted for $15 \%$ beyond the Ladder. Together Affect Balance and the Ladder predict $57 \%$ of the variance in the Happiness of nations.

The intercorrelations of the well-being variables at the individual level are shown in the lower portion of Table 1. Note that the happiness scale was not included in the 
Gallup World Poll. As can be seen, the correlations are lower than those for nations, perhaps because there is more measurement error and situational variability in individual responses. The intercorrelations of the measures indicate a consistently strong correlation between the Ladder and Life Satisfaction, and a weaker correlation of those variables with Affect Balance. Happiness tends to correlate more strongly with Affect Balance than do either Life Satisfaction or the Ladder.

Insert Table 1 About Here

A set of regression analyses in which Life Satisfaction was predicted by the other two variables at the individual level indicated that it was most closely associated with the Ladder, but that Affect Balance added significantly to its prediction as well (all p's < .001). When the Ladder was entered first as a predictor, it accounted for 37 percent of the variance, and Affect Balance added 2 percent more to the prediction when it was added. In contrast, when Affect Balance was entered first entered as a predictor, it explained 8 percent of the variance in Life Satisfaction, but the Ladder added 31 percent additional variance. Thus, at the individual level as at the nation level Life Satisfaction was both a judgment and affect variable, but much more strongly saturated with judgment. Happiness also has a substantial judgment component, but a considerable amount of affect as well. This conclusion is strengthened when the correlates of well-being with other types of measures are examined. 
We next analyzed the correlations of the four well-being measures with three predictors, and these associations are shown in Table 2 . All income values were transformed to Log10 values. As can be seen, the Ladder correlated significantly more highly with income and conveniences and significantly lower with choosing how to spend one's time than the other SWB variables. In some cases the correlations of Life Satisfaction with the predictors differed from those for Happiness and Affect Balance, and in some cases not. Affect Balance and Happiness never differed significantly from each other. The pattern of correlations clearly indicates that income and conveniences are more strongly associated with well-being judgments, and that feelings tend to be more strongly associated with the perceived freedom to choose how to spend one's time. As can be seen, the relation of income to the well-being variables was similar at the two points in time. Although we are uncertain what feeling free in terms of spending one's time indicates, the important point here is that it correlated in a pattern opposite to that of the material variables.

Insert Table 3 About Here

Table 3 presents the correlations at the individual level of the well-being variables with the predictors shown in Table 2 . Because of the very large samples sizes, all correlations shown in the table differ significantly from one another by $p<.001$. The correlations with the material variables and well-being, as well as feelings of autonomy and well-being, all mirror the pattern of associations found at the nation level. The correlations, however, are again lower than those found with the nation-level variables. 
Taken together these results indicate that Life Satisfaction is closer to the Ladder, and Happiness is closer to Affect Balance.

\section{$\underline{\text { Longitudinal Analyses }}$}

We examined the correlations of each of the well-being measures with income and income change over periods of time greater than five years. In Table 4 we present the means for income and the well-being variables at the two points in time, as well as the average year of the surveys. As can be seen, on average the surveys were many years apart, with intervals of 37, 21, and 18 years for three well-being measures. Furthermore, there were large increases in income over those periods of time. Thus, if rising income has a long-term effect on well-being, it should be apparent during the prosperous periods of time we analyzed. We correlated the long-term change in log per capita income with the change in well-being, and found associations of: Ladder, $r=.54, \mathrm{~N}=19, p<.05$; Life Satisfaction, $r=.25, \mathrm{~N}=50, p=.08$; Happiness, $r=-.13, \mathrm{~N}=58, p=.34$.

\section{Insert Table 4 About Here}

How large and consistent were the changes in well-being? Because income substantially increased, there ought to be a recognizable overall increase in well-being, not simply a correlation with changes in income, if income influences well-being. All three measures of well-being increased significantly from T1 to T2, all p's $<.01$. When the scale score changes are expressed in terms of the between-nation standard deviations in scores, well-being changed the following amount: Ladder $=.69$ SD units; Life Satisfaction $=.25$ SD units; and Happiness $=.41$ SD units. As percentages of the total possible range of the scales, the differences between Times 1 and 2 were: Ladder $=7$ 
percent; Life Satisfaction $=3$ percent; and Happiness $=4$ percent. Thus, the Ladder changes over time were larger both in standard deviation units, but also in terms of moving across more of the range of the scale. In keeping with the conclusions of Inglehart (2009), however, we did find that in general well-being rose on average during the several decade period we studied.

Our final analysis examined the regression of GDP on the Ladder at both Time 1 and 2. A comparison of the intercepts of the two regressions provides a test of whether there is adaptation to income. If there is adaptation, the same level of income should provide less well-being at time 2 than at time 1. As can be seen in Figure 1, the regressions are effectively identical. Although GDP more than doubled between the two measurements, the relation between the ladder and national income did not change. The analyses reported by Deaton (2008) and Stevenson and Wolfers (2008) suggested strongly that in the recent GWP people all over the world compared themselves to a common standard of material well-being. The findings of Figure 1 suggest further that this standard has not changed appreciably over the last three decades. This does not mean that the standard cannot move, but it does suggest that at least in this case there was a relatively consistent material standard for the ideal life in material terms.

\section{Insert Figure 1 About Here}

\section{$\underline{\text { Discussion }}$}

Our findings indicate that measures of well-being vary along a dimension that is anchored by judgments about one's life at one end and by affect at the other. Selected measures can be placed on this continuum based on the relative amount they are 
influenced by the two types of subjective well-being. Cantril's Ladder of Life appears to reflect a judgment about one's life, whereas reports of emotions during the previous day are located toward the other end of the dimension. Life Satisfaction is between the two anchors, but close to the Ladder, primarily reflecting a judgment, and this conclusion is consistent with the findings of Helliwell et al. (2009). Reports of "happiness" also fall toward the middle of the dimension, but closer to the affective end than does Life Satisfaction. We suspect that the feelings end of the dimension is anchored by experience-sampling measures of momentary feelings.

Not only do the measures differ in their relations with each other, but they also differ in their strength of association with variables such as income and the ownership of modern conveniences. The Ladder was mostly strongly correlated with these material variables, and the Affect Balance measure was least strongly associated with them. Life Satisfaction was significantly more strongly related to the material variables than was Affect Balance. The strength of associations for Happiness and the material variables was significantly weaker than the Ladder correlations.

In contrast to the material variables, feelings of autonomy in everyday life were more strongly associated with affect and less strongly associated with the Ladder. Thus, at both the individual and nation levels the pattern of correlations with the predictors confirms the dimensional ordering derived from the intercorrelations of the well-being variables with each other. The correlations suggest that material prosperity is strongly associated with judgments of life but much less correlated with affective well-being.

An examination of changes in well-being and income over time again supports the separability of the measures along the judgment-affect dimension. Changes in the Ladder 
scores over time showed a clear association with changes in income, whereas the strength of this association for happiness and life satisfaction was weaker.

Is Easterlin or are his critics correct? Over the long-term life judgments of life were strongly related to income and rose with income. On the other hand, affect benefited less from long-term rising income. One can point to the increases in well-being that have occurred in most nations, or one can point to a number of nations that have declined in well-being even as their incomes have risen. Clearly, more factors influence well-being than simply changes in income. For example, Inglehart (2009) in this volume points to the fact that political freedom and income can move in different directions, and therefore produce countering forces on well-being. Our findings are consistent with those of Inglehart in suggesting that the well-being of nations can indeed change over time, and that certain forms of well-being are more likely to change in association with changes in income. In addition, other factors in societies besides income must be considered, such as social trust and urbanization, and psychological factors such as rising aspirations might also play a role. Easterlin was correct in his claim that rising incomes do not invariably increase subjective well-being. However, his critics are correct in their claim that rising incomes have on average been associated with some increases in at least some forms of well-being. The challenge now is to understand when income helps well-being and when it does not, as well as how changes in other societal characteristics influence the various types of well-being.

One conclusion that is certain from our findings is that it is no longer productive to talk about income and general "happiness;" at the very least well-being must be parsed into the judgmental versus affective components. Whether rising income improves the 
human lot appears to depend at least in part on the types of well-being being assessed. In a related paper (Kahneman, Diener, Arora, Muller, Harter, \& Tov, 2009), we separately analyze positive and negative affect, and show that even for feelings the associations with other variables can differ systematically.

The current findings raise many issues for future study. An important question is what are the factors most responsible for changes in affect in nations. The fact that the same regression line described the relationship between the Ladder and GDP in measurements taken on average 37 years apart also deserves detailed study. Although we have focused on the different types of well-being measures, more sophisticated measures of wealth, income, and consumption are also needed. It will also be important to determine whether there are factors associated with rising income such as democratization that produce some of the well-being effects, and conversely, whether rapidly rising national incomes are associated with negative changes in some aspects of the quality of life, including residential dislocation. 


\section{References}

Cantril, H. (1965). The pattern of human concerns. New Brunswick, NJ: Rutgers University Press.

Deaton, A. (2008). Income, health, and well-being around the world: Evidence from the Gallup World Poll. Journal of Economic Perspectives, 22, 53-72.

Easterlin, R. A. (1974). Does economic growth improve the human lot? Some empirical evidence. In P. A. David \& M. W. Reder (Eds.), Nations and households in economic growth. New York: Academic Press.

Easterlin, R.A. (2005). Feeding the illusion of growth and happiness: A reply to Hagerty and Veenhoven. Social Indicators Research, 74, 429-443.

Hagerty, M., \& Veenhoven, R. (2003). Wealth and happiness revisited - growing national income does go with greater happiness. Social Indicators Research, 64, 1 27.

Helliwell, J.F., Barrington-Leigh, C., Harris, A., \& Huang, H. (2009). International evidence on the social context of well-being. In E. Diener, D. Kahneman, and J.F. Helliwell (Eds.), International Differences in Well-Being. Oxford, UK: Oxford University Press.

Inglehart, R., Foa, R., Peterson, C., \& Welzel, C. (2008). Development, freedom, and rising happiness: A global perspective (1981-2007). Perspectives on Psychological Science, 3, 264-285.

Inglehart, R. (2009). Faith and freedom: Traditional and modern ways to happiness. In E. Diener, D. Kahneman, and J.F. Helliwell (Eds.), International Differences in Well-Being. Oxford, UK: Oxford University Press.

Kahneman, D. (1999). Objective happiness. In D. Kahneman, E. Diener, \& N. Schwarz (Eds.), Well-being: The foundations of hedonic psychology. New York: Russell Sage Foundation.

Kahneman, D., Diener, E., Arora, R., Muller, G., Harter, J., \& Tov, W. (2009). Prosperity and well-being on planet earth. To be submitted to Proceedings of the National Academy of Sciences (PNAS).

Lucas, R. E., Diener, E., \& Suh, E. (1996). Discriminant validity of well-being measures. Journal of Personality and Social Psychology, 71, 616-628. 
Maddison, A. (September 3, 2007). Statistics on world population, GDP, and per capita GDP, 1-2006 AD. In Angus Maddison (faculty homepage). Retrieved November 29, 2008, from http://www.ggdc.net/maddison/.

Stevenson, B., \& Wolfers. J. (April 15, 2008). Economic growth and subjective wellbeing: Reassessing the Easterlin Paradox. Working Paper Series. Available at SSRN: http://ssrn.com/abstract=1121237

Veenhoven, R. (2008). World database of happiness, Trends in nations. Roterdam: Erasmus University, September 10, 2008. http://worlddatabaseofhappiness.eur.nl/

Veenhoven, R., \& Hagerty, M. (2006). Rising happiness in nations 1946-2004. Social Indicators Research, 79, 421-436. 
Table 1: Intercorrelations of Well-Being Measures

\begin{tabular}{|c|c|c|c|}
\hline $\begin{array}{l}\text { Well-Being } \\
\text { Variables }\end{array}$ & Ladder & $\begin{array}{l}\text { Life } \\
\text { Satisfaction }\end{array}$ & Happiness \\
\hline \multicolumn{4}{|l|}{$\underline{\text { Across Nations }}$} \\
\hline Life Satisfaction & $\begin{array}{c}.82 \\
\mathrm{~N}=63\end{array}$ & & \\
\hline Happiness & $\begin{array}{c}.64 \\
N=61\end{array}$ & $\begin{array}{c}.68 \\
\mathrm{~N}=41\end{array}$ & \\
\hline Affect Balance & $\begin{array}{c}.55 \\
N=126\end{array}$ & $\begin{array}{c}.62 \\
\mathrm{~N}=61\end{array}$ & $\begin{array}{c}.70 \\
\mathrm{~N}=60\end{array}$ \\
\hline \multicolumn{4}{|l|}{$\underline{\text { Across Individuals }}$} \\
\hline Life Satisfaction & $\begin{array}{l}.57 \\
N=55,057\end{array}$ & & \\
\hline Affect Balance & $\begin{array}{l}.25 \\
\mathrm{~N}=105,126\end{array}$ & $\begin{array}{c}.31 \\
\mathrm{~N}=51,485\end{array}$ & \\
\hline
\end{tabular}

Note. Correlations across individuals consist only of data from Wave 2 of the Gallup World Poll. 
Table 2

Nation-Level Correlates of Well-Being

\begin{tabular}{|c|c|c|c|}
\hline Well-Being & Income Per & Choose How to & Possession of Modern \\
\hline Variables & Capita & Spend Time & Conveniences \\
\hline
\end{tabular}

$\underline{\text { Ladder Score }}$

Time $1 \quad .74_{\mathrm{a}}$

$\mathrm{N}=19$

Time $2 \quad .83_{\mathrm{a}}$

$\mathrm{N}=126$

$.30_{\mathrm{a}}$

$\mathrm{N}=130$

$.78_{\mathrm{a}}$

$\mathrm{N}=91$

$\underline{\text { Life Satisfaction }}$

Time $1.69_{\mathrm{b}}$

$\mathrm{N}=29$

Time $2 \quad .56_{\mathrm{b}}$

$\mathrm{N}=64$

$.49_{\mathrm{b}}$

$\mathrm{N}=63$ $.42_{\mathrm{b}}$

$\mathrm{N}=32$

$\underline{\text { Happiness }}$

Time $1 \quad .31_{\mathrm{c}}$

$\mathrm{N}=53$

Time $2.42_{\mathrm{c}}$

$\mathrm{N}=60$

$.43_{\mathrm{ab}}$

$\mathrm{N}=61$

$.03_{\mathrm{bc}}$

$\mathrm{N}=33$

Affect Balance $\quad .31_{\mathrm{c}}$

(Time 2 only) $\quad \mathrm{N}=122$

$.56_{\mathrm{b}} \quad .14_{\mathrm{c}}$

$\mathrm{N}=126$

$\mathrm{N}=90$

Note: Correlations for the same time period in the same column who do not share a subscript letter in common differ by $p<.05$ or less. 


\section{Table 3}

Individual-Level Correlates of Well-Being

Well-Being

Variables
Income

Ladder Score

.40

$$
\mathrm{N}=77,213
$$

.33

$$
\mathrm{N}=34,771
$$

.14

$$
\mathrm{N}=72,572
$$

Affect Balance

Life Satisfaction

All correlations are significant at $p<.01$, and all correlations in the same column are significantly different from one another at $p<.01$
Possession of Modern Conveniences 
Table 4

Means and Standard Deviations of Key Variables for Both Waves

\begin{tabular}{|c|c|c|c|}
\hline Wave \& Variables & $\underline{\text { Ladder }}$ & $\underline{\text { Life Satisfaction }}$ & $\underline{\text { Happiness }}$ \\
\hline Wave 1 Well-Being & $\begin{array}{l}5.60 \\
(1.06)\end{array}$ & $\begin{array}{l}6.32 \\
(1.28)\end{array}$ & $\begin{array}{l}2.96 \\
(.29)\end{array}$ \\
\hline Wave 2 Well-Being & $\begin{array}{l}6.30 \\
(.96)\end{array}$ & $\begin{array}{l}6.63 \\
(1.08)\end{array}$ & $\begin{array}{l}3.08 \\
(.26)\end{array}$ \\
\hline Wave 1 Year & $\begin{array}{l}1969 \\
(10.1)\end{array}$ & $\begin{array}{l}1985 \\
(10.2)\end{array}$ & $\begin{array}{l}1987 \\
(10.5)\end{array}$ \\
\hline Wave 2 Year & $\begin{array}{c}2006 \\
--\end{array}$ & $\begin{array}{l}2006 \\
(1.8)\end{array}$ & $\begin{array}{l}2005 \\
(2.8)\end{array}$ \\
\hline Wave 1 GDP/capita & $\begin{array}{l}4,524 \\
(2.69)\end{array}$ & $\begin{array}{l}7,279 \\
(2.02)\end{array}$ & $\begin{array}{l}7,244 \\
(2.14)\end{array}$ \\
\hline Wave 2 GDP/capita & $\begin{array}{l}10,506 \\
(2.52)\end{array}$ & $\begin{array}{l}11,277 \\
(2.16)\end{array}$ & $\begin{array}{l}10,513 \\
(2.29)\end{array}$ \\
\hline $\begin{array}{c}\text { Number of Nations } \\
\text { at Both Waves }\end{array}$ & 19 & 50 & 53 \\
\hline
\end{tabular}

Note: For GDP/capita we present the geometric mean (geometric SD) because logged values were used in all analyses. 
Figure 1. National Mean Ladder Scores by Log GDP per Capita at Times 1 and 2

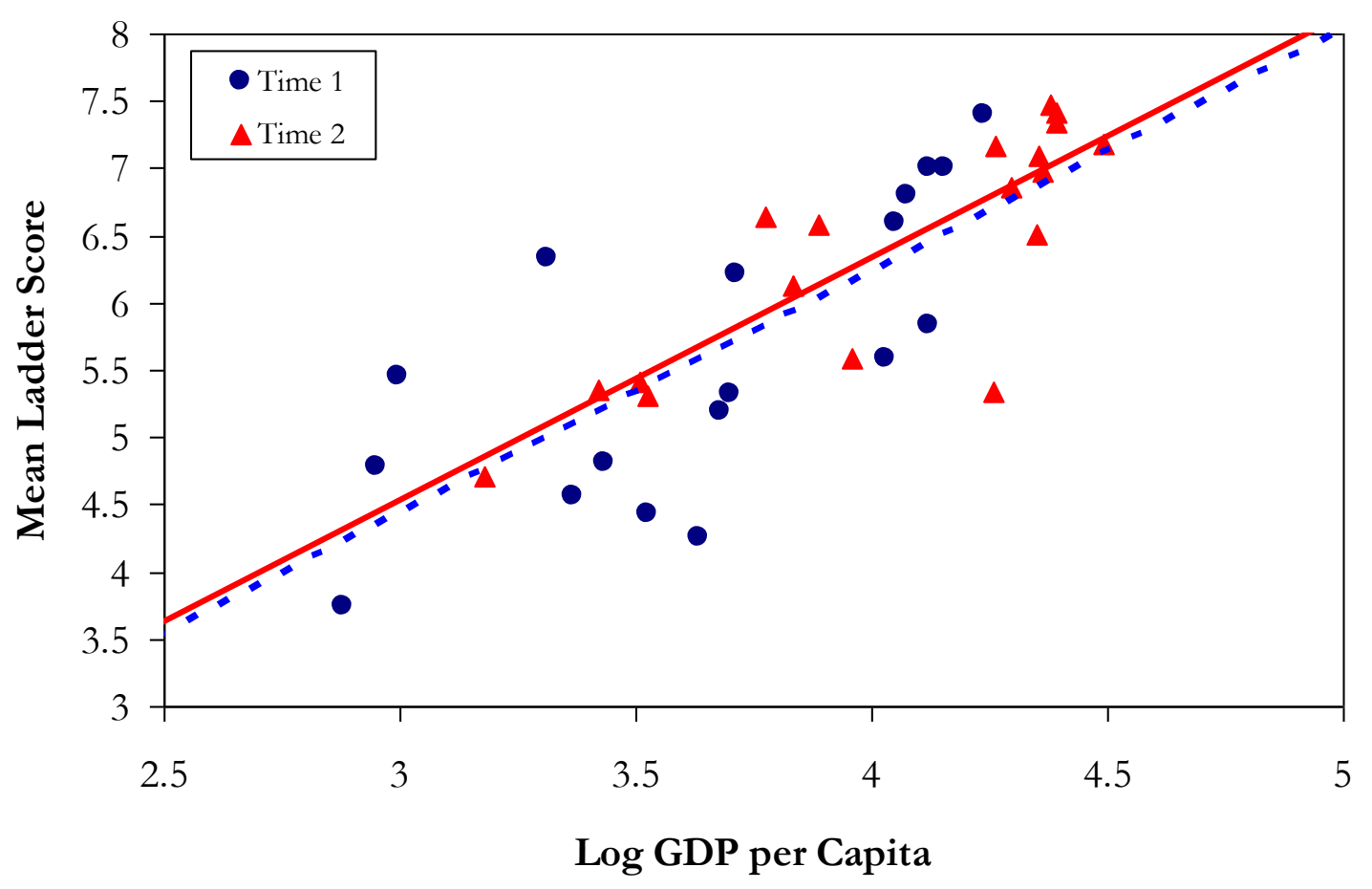

